\title{
Absorption of Sulphur by Liquid Slags from Gas Phase under a Reducing Atmosphere*
}

\author{
By Kensuke SASSA, ${ }^{* *}$ Michihide ANDOH, ${ }^{* * *}$ Takao $\mathrm{CHOH}^{* *}$ and \\ Michio INOUYE**
}

\section{Synopsis}

The rates of sulphur transfer from gas to liquid slags were studied under a reducing atmosphere. $\mathrm{Ar}-\mathrm{H}_{2} \mathrm{~S}$ gas mixture was introduced to the surface of such liquid slags as $\mathrm{CaO}-\mathrm{Al}_{2} \mathrm{O}_{3}$ and $\mathrm{CaO}-\mathrm{SiO}_{2}-\mathrm{Al}_{2} \mathrm{O}_{3}$ slags at $1550^{\circ} \mathrm{C}$.

The results obtained are summarized as follows:

(1) The rates of sulphur transfer from $\mathrm{Ar}-\mathrm{H}_{2} \mathrm{~S}$ gas mixture to liquid slag were proportional to the partial pressure of hydrogen sulphide and to the flow rate of gas mixture.

(2) If the slags were melted in a graphite crucible, the rates of sulphur absorption by $\mathrm{CaO}-\mathrm{SiO}_{2}$ binary slags were higher than those by $\mathrm{CaO}-$ $\mathrm{Al}_{2} \mathrm{O}_{3}$ slags.

(3) The rates of sulphur absorption by $\mathrm{CaO}-\mathrm{SiO}_{2}-\mathrm{Al}_{2} \mathrm{O}_{3}$ ternary slags contained in a graphite crucible could be represented as a function of the activities of $\mathrm{CaO}$ and $\mathrm{SiO}_{2}$. A linear relationship was obtained between the rate of sulphur absorption and the activity of $\mathrm{CaO}$, when the activity of $\mathrm{SiO}_{2}$ was taken as a parametre. In addition, it was generally observed that the rates increased with increasing activity of $\mathrm{SiO}_{2}$ under the constant activity of $\mathrm{CaO}$.

(4) In view of other experimental results, it was also clear that the interfacial reaction between graphite crucible and liquid slag would have some influences on the rate of sulphur transfer. Although the sulphur transfer was accelerated by the reduction of $\mathrm{SiO}_{2}$ by graphite, it was retarded by the dissolution of graphite into liquid slag.

\section{Introduction}

Recently, the investigation was undertaken on the reactions taken place in the blast furnace and it has been found that the behaviour of sulphur between gas and metal in the blast furnace is particularly noteworthy as well as the reaction of sulphur between liquid slag and metal.

Studies on the behaviour of sulphur in the blast furnace were conducted by many investigators. However, available informations on the transfer of sulphur from the gas phase are not sufficient enough. Recently, from the dissection of a blast furnace, ${ }^{1)}$ it was found that both slag and reduced iron fairy absorbed sulphur from the gas phase until they reached to the bosh. Although there is no doubt that the desulphurization in the blast furnace mainly proceeds with the reaction between slag and metal, further informations on the mechanism of the transfer of sulphur from the gas phase is desired in order to analyse the behaviour of sulphur in the blast furnace.

The present work is aimed to study the transfer of sulphur from the gas phase under a reducing atmosphere.

\section{Reaction of Sulphur in Liquid Slag and Gas}

The equilibrium of the reaction of sulphur between liquid slag and gas was investigated by F. D. Richardson and J. B. Fincham., ${ }^{2,3)}$ They showed that the concentration of sulphur in liquid slag is controlled by the partial pressures of sulphur and oxygen in the gas phase. Also, their results showed that all the sulphur in the slag exists in the form of sulphide when the partial pressure of oxygen in the gas phase is less than $10^{-5} \sim 10^{-6} \mathrm{~atm}$. They also defined the sulphide capacity of a melt, $C_{s}$, as follows :

$$
C_{s}=(\mathrm{wt} \% \mathrm{~S}) \cdot\left(p_{\mathrm{O}_{2}}\right)^{1 / 2} \cdot\left(p_{\mathrm{S}_{2}}\right)^{1 / 2}
$$

Here, if $p_{\mathrm{O}_{2}}$ is larger than $10^{-3} \sim 10^{-4}$ atm, the capacity of the melt to hold sulphur as sulphate is exfollowing pressed by the following sulphate capacity:

$$
C_{\mathrm{SO}_{4}}=(\mathrm{wt} \% \mathrm{~S}) \cdot\left(p_{\mathrm{O}_{2}}\right)^{3 / 2} \cdot\left(p_{\mathrm{S}_{2}}\right)^{1 / 2}
$$

Namely the form of sulphur in the slag changes from $\mathrm{S}^{2-}$ to $\mathrm{SO}_{4}^{2-}$ as $p_{\mathrm{O}_{2}}$ increases.

On the other hand, E. T. Turkdogan and M. L. Pearce $^{4)}$ studied the kinetics of sulphur transfer from such gases containing sulphur as $\mathrm{CO}-\mathrm{CO}_{2}-\mathrm{SO}_{2}$ mixtures to liquid slag in platinum or iridium crucibles. They showed that when the depth of the melt was 10 to $15 \mathrm{~mm}$, the transport of sulphur in the melt became the rate controlling step, while the depth of the melt was 1 to $4 \mathrm{~mm}$, the rate of sulphur transfer was controlled by the diffusion or the chemical reaction.

Furthermore they showed that, when sulphur dissolves into $\mathrm{FeO}-\mathrm{SiO}_{2}(60-40)$ slag, the concentration of sulphur in the slag increases with the elapse of time showing a maximum value, since the sulphurization proceeds predominantly as compared with the oxidation.

On the other hand, A. S. Alwan and P. M. Bills ${ }^{5)}$ studied the absorption of sulphur in $\mathrm{FeO}-\mathrm{CaO}-\mathrm{SiO}_{2}$, $\mathrm{FeO}-\mathrm{CaO}$ and $\mathrm{FeO}-\mathrm{SiO}_{2}$ liquid slags from $\mathrm{CO}-$ $\mathrm{CO}_{2}-\mathrm{SO}_{2} \quad\left(p_{\mathrm{S}_{2}}=2.8 \times 10^{-2} \mathrm{~atm}, \quad p_{\mathrm{O}_{2}}=10^{-8} \mathrm{~atm}\right)$ gas mixtures. They found that the concentration of free oxygen ion in the melt would be a significant factor on the rate and the extent of sulphur absorption, namely, they decrease with decreasing amount of free oxygen ion. They also concluded that the rate of sulphur transfer from gas to liquid slag was limited by diffusion of $\mathrm{S}^{2-}$ through the silicate network of the slag.

These works were carried out by assuming the steelmaking process; however, investigations on the

* Originally published in Tetsu-to-Hagané, 63 (1977), 2299, in Japanese. English version received March 2, 1978.

** Faculty of Engineering, Nagoya University, Furo-cho, Chikusa-ku, Nagoya 464.

*** Kimitsu Works, Nippon Steel Corp., Kimitsu, Kimitsu 299-11. 
sulphur absorption at reducing atmosphere simulating blast furnace are still continued up to the present.

\section{Experimental Procedure}

A schematic diagram of the apparatus used is shown in Fig. 1 and the detail of the reaction furnace is shown in Fig. 2.

In this work $\mathrm{Ar}-\mathrm{H}_{2} \mathrm{~S}$ gas mixture was mainly used. The synthetic slag of $100 \mathrm{~g}$ was melted by an induction furnace in a graphite crucible of $40 \mathrm{~mm}$ (inner diametre) under an argon atmosphere. At a definite temperature, $\mathrm{Ar}-\mathrm{H}_{2} \mathrm{~S}$ gas mixture was introduced to the surface of liquid slag which was stirred by a graphite stirrer with two blades. The samples were taken by an iron bar at definite time intervals. All samples were analysed for sulphur by the combustion method.

The synthetic slags were prepared by melting the mixtures of extra pure reagents of $\mathrm{CaO}, \mathrm{SiO}_{2}$ and $\mathrm{Al}_{2} \mathrm{O}_{3}$ in a graphite crucible. Since the results of chemical analysis for a few synthetic slags were nearly the same to the predetermined composition of mix-

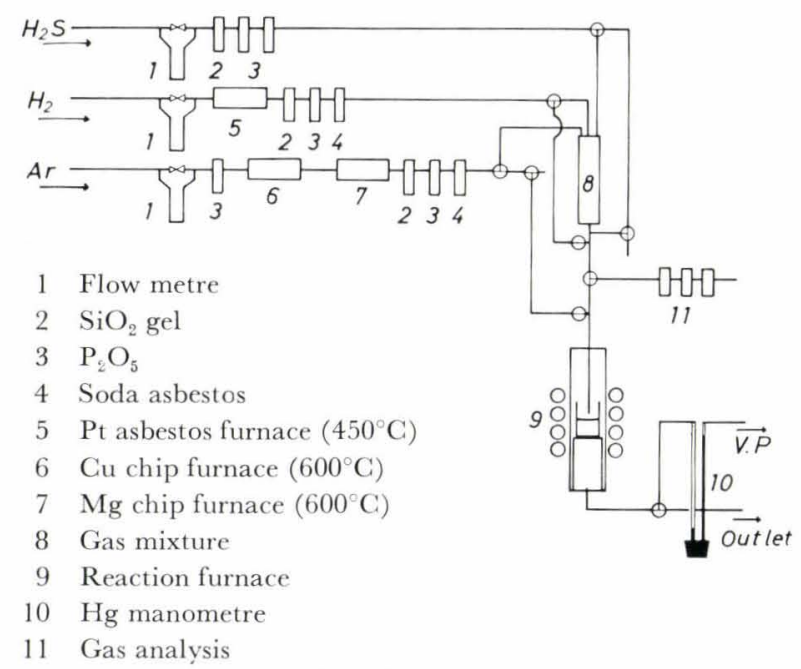

Fig. 1. Experimental apparatus

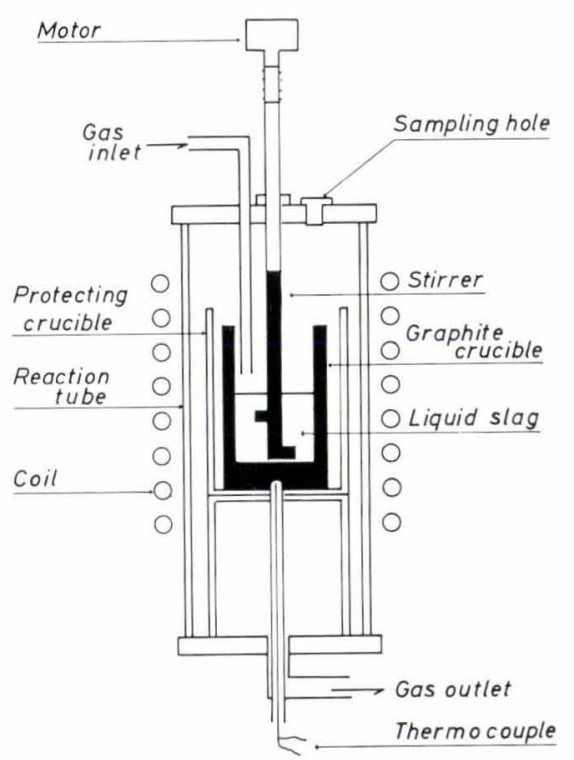

Fig. 2. Reaction furnace ture, for example, the results of analysis of $\mathrm{CaO}$ $\mathrm{SiO}_{2}$ (55-45), $\mathrm{CaO}-\mathrm{SiO}_{2}(45-55)$ and $\mathrm{CaO}-\mathrm{SiO}_{2}-$ $\mathrm{Al}_{2} \mathrm{O}_{3}$ (50-35-15) slags were (55.20-43.88), (44.0553.16) and (49.78-35.03-15.19) respectively, the slag composition was shown by the predetermined composition of the mixture in the current work.

\section{Result}

\section{Effect of Stirring Rate}

In order to know the influence of stirring of the melt on the rate of sulphur absorption, some experiments were conducted by changing the stirring rate from 50 to $1100 \mathrm{rpm}$ with the $\mathrm{CaO}-\mathrm{SiO}_{2}$ (55-45) and $\mathrm{CaO}-\mathrm{Al}_{2} \mathrm{O}_{3}(55-45)$ slags at $1550^{\circ} \mathrm{C}$. The gas mixture introduced to the system was $\mathrm{Ar}-\mathrm{H}_{2} \mathrm{~S}\left(p_{\mathrm{H}_{2} \mathrm{~S}}=\right.$ $0.01 \mathrm{~atm})$ and the results obtained are shown in Fig. 3. From this figure, it is evident that the rate of sulphur absorption increases with increasing stirring rate if the stirring rate is below $500 \mathrm{rpm}$. It is also observed that the rate of sulphur absorption is independent of the stirring rate when the rate is more than $500 \mathrm{rpm}$. Therefore the further experiments were conducted under the constant stirring rate of $800 \mathrm{rpm}$.

\section{Effect of Partial Pressure of $\mathrm{H}_{2} \mathrm{~S}$}

Under the gas flow rate of $1000 \mathrm{cc} \cdot \mathrm{min}^{-1}$ and the stirring rate of $800 \mathrm{rpm}$, the rates of sulphur absorption by the $\mathrm{CaO}-\mathrm{SiO}_{2}(55-45), \mathrm{CaO}-\mathrm{SiO}_{2}-\mathrm{Al}_{2} \mathrm{O}_{3}$ (27-20-53) and $\mathrm{CaO}-\mathrm{SiO}_{2}-\mathrm{Al}_{2} \mathrm{O}_{3}(38-42-20)$ slags were measured by changing the partial pressures of $\mathrm{H}_{2} \mathrm{~S}$ in the reaction gas from $0.25 \times 10^{-2}$ to $2.00 \times$ $10^{-2}$ atm.

The results obtained are shown in Fig. 4 which indicates that the rate of absorption increases with increasing partial pressure of $\mathrm{H}_{2} \mathrm{~S}$, and also depends on the slag composition. In the case that the $p_{\mathrm{H}_{2} \mathrm{~S}}$ was kept constant at 0.01 atm and the $p_{\mathrm{H}_{2}}$ was changed in the range of 0 to $0.75 \mathrm{~atm}$, the effect of the partial pressure of hydrogen on the rate of sulphur absorption from $\mathrm{Ar}-\mathrm{H}_{2} \mathrm{~S}-\mathrm{H}_{2}$ gas mixture by the $\mathrm{CaO}-\mathrm{SiO}_{2}$ (55-45) slag was not observed.

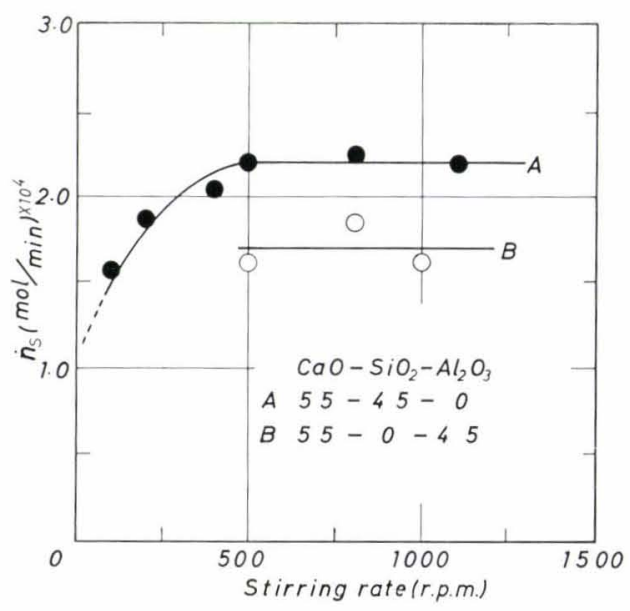

Fig. 3. Effect of stirring rate on the rate of sulphur absorption into slag at $1550^{\circ} \mathrm{C}$ 


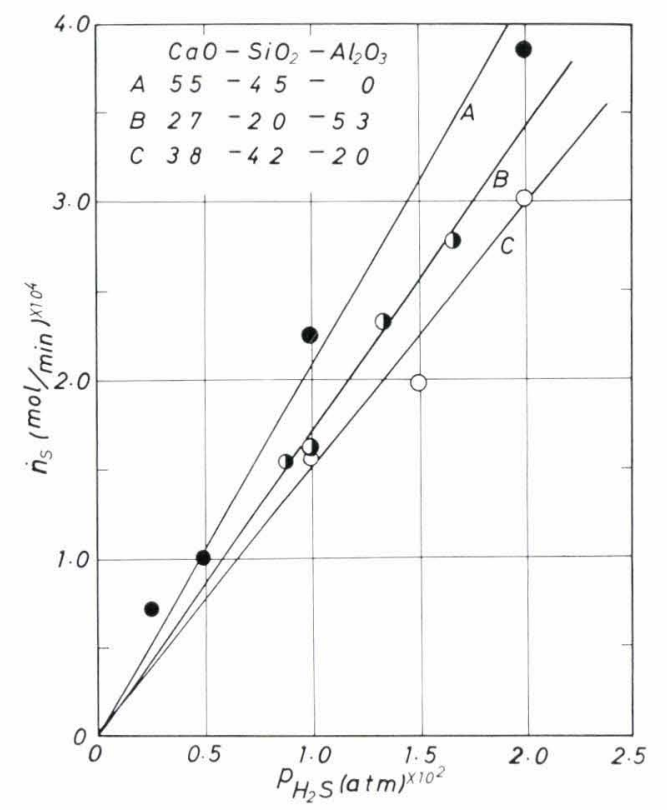

Fig. 4. Effect of $p_{\mathrm{H}_{2} \mathrm{~S}}$ on the rate of sulphur absorption into liquid slag at $1550^{\circ} \mathrm{C}$

\section{Effect of Gas Flow Rate}

The rate of sulphur absorption by the $\mathrm{CaO}-\mathrm{SiO}_{2}$ (55-45) binary slag was measured by changing the flow rate of reaction gas from 250 to $1500 \mathrm{cc} \cdot \mathrm{min}^{-1}$ under constant stirring rate of bath, partial pressure of hydrogen sulphide $p_{\mathrm{H}_{2} \mathrm{~S}}$ and temperature which are $800 \mathrm{rpm}, 0.01 \mathrm{~atm}$ and $1550^{\circ} \mathrm{C}$, respectively.

The results obtained show that the amount of sulphur picked up by slag linearly increases and the effect of the flow rate of gas is significant as shown in Fig. 5 which indicates that the rate of sulphur absorption increases with increasing gas flow rate.

\section{Effect of Slag Composition}

One of the most important aim of the present work is to find the effect of slag composition on the rate of sulphur absorption from the gas phase. As described above, it was found that the rate of sulphur absorption depends on the gas flow rate and the partial pressure of $\mathrm{H}_{2} \mathrm{~S}$ when the composition of liquid slag is the same. Here, the effect of slag composition on the rate of sulphur absorption was measured at $1550^{\circ} \mathrm{C}$, under the following experimental conditions:

$$
\begin{array}{ll}
\text { the gas flow rate: } & 1000 \mathrm{cc} \cdot \mathrm{min}^{-1} \\
\text { the stirring rate: } & 800 \mathrm{rpm} \\
\text { the partial pressure of } \mathrm{H}_{2} \mathrm{~S}: & 0.01 \mathrm{~atm}
\end{array}
$$

\section{Absorption of Sulphur in $\mathrm{CaO}-\mathrm{SiO}_{2}$ and $\mathrm{CaO}-\mathrm{Al}_{2} \mathrm{O}_{3}$ Binary Slags}

The rates of sulphur absorption by $\mathrm{CaO}-\mathrm{SiO}_{2}$ and $\mathrm{CaO}-\mathrm{Al}_{2} \mathrm{O}_{3}$ binary slags decrease with increasing $\mathrm{SiO}_{2}$ or $\mathrm{Al}_{2} \mathrm{O}_{3}$ content of the slag, as shown in Fig. 6. It is also observed that the rate of sulphur absorption by $\mathrm{CaO}-\mathrm{SiO}_{2}$ slag is larger than that by $\mathrm{CaO}-$ $\mathrm{Al}_{2} \mathrm{O}_{3}$ slag in the range of higher $\mathrm{CaO}$ concentration. However, the difference between the rates of sulphur absorption by the slags becomes smaller with de-

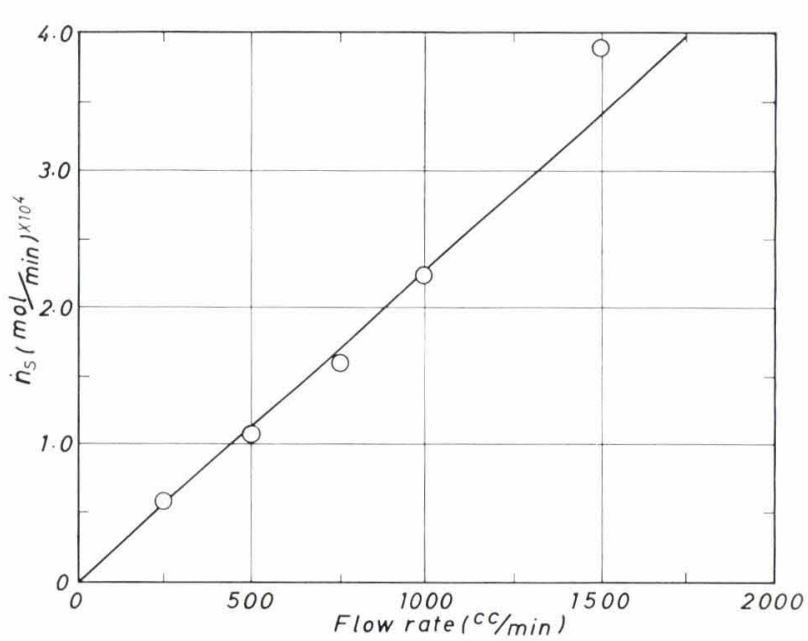

Fig. 5. Effect of flow rate of $\mathrm{Ar}-\mathrm{H}_{2} \mathrm{~S}$ gas on the rate of sulphur absorption into slag at $1550^{\circ} \mathrm{C}$

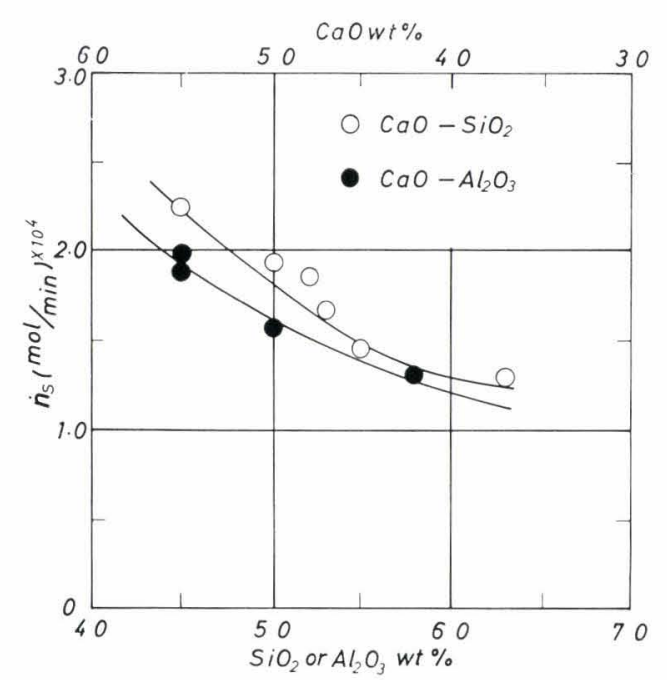

Fig. 6. Effect of binary $\mathrm{CaO}-\mathrm{SiO}_{2}$ and $\mathrm{CaO}-\mathrm{Al}_{2} \mathrm{O}_{3}$ slags on the rate of sulphur absorption at $1550^{\circ} \mathrm{C}$

creasing $\mathrm{CaO}$ concentration.

\section{Sulphur Absorption by Slags at Constant $\mathrm{CaO}$ Con-} centration

Results obtained by using the $\mathrm{CaO}-\mathrm{SiO}_{2}-\mathrm{Al}_{2} \mathrm{O}_{3}$ ternary slags containing $50 \mathrm{wt} \% \mathrm{CaO}$ were shown in Fig. 7. It can be seen from the figure that sulphur is picked up more rapidly by the ternary slags than by the binary slags which were described in $I V$. 4. 1 . The same trends were observed for the slags of 45 $\mathrm{wt}_{\mathrm{o}} \mathrm{CaO}$.

3. Effect of Activity of Silica on the Rate of Sulphur Absorption by Liquid Slag at Constant Activity of Lime

Taking the activity of lime as a parametre, the relationship between the rate of sulphur absorption and the logarithmic value of $a_{\mathrm{SiO}_{2}}$ is shown in Fig. 8, in which solid circles show the results obtained by using a graphite crucible. Here, the values determind by J. Chipman and R. H. Rein ${ }^{6)}$ were used for the activities of lime and silica in the slag.

The results show that, as expected, the rate of sulphur absorption increases with increasing activity of lime. It is also found that, when the activity of 


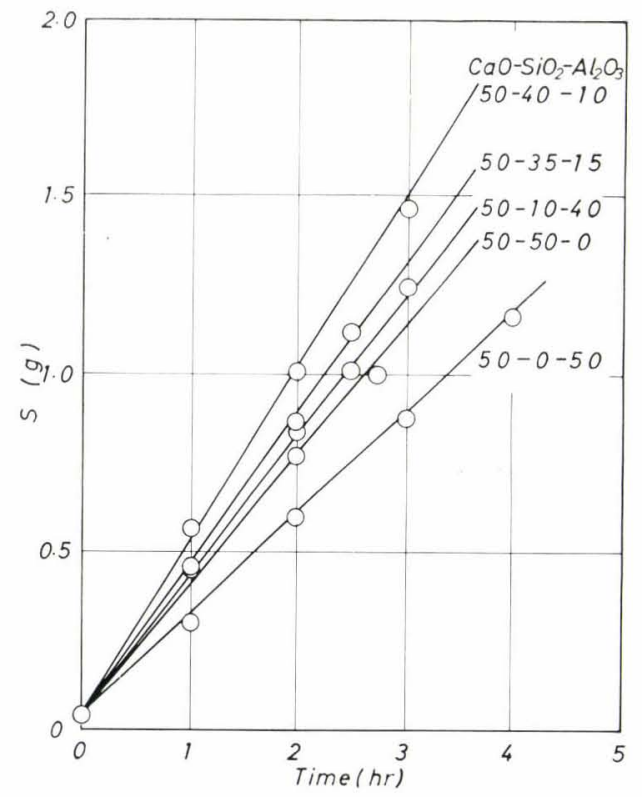

Fig. 7. Rate of sulphur absorption into ternary $\mathrm{CaO}-\mathrm{SiO}_{2}$ $\mathrm{Al}_{2} \mathrm{O}_{3}$ slag with $50 \mathrm{wt} \% \mathrm{CaO}$ at $1550^{\circ} \mathrm{C}$

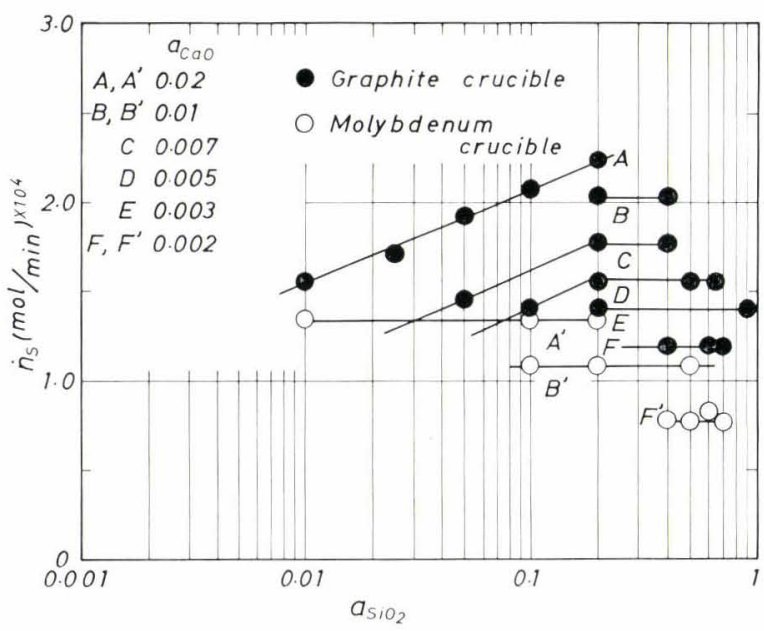

Fig. 8. Relation between $a_{\mathrm{SiO}}$ and the rate of sulphur absorption at $1550^{\circ} \mathrm{C}$

lime is constant, the rate of sulphur absorption increases as the activity of silica increases to 0.2 , and that, when the activity of silica is above 0.2 , the rate of sulphur absorption becomes constant.

Similarly, the rates of sulphur absorption were plotted against the logarithmic value of $a_{\mathrm{CaO}}$ and are shown in Fig. 9 taking $a_{\mathrm{SiO}_{2}}$ as a parametre. A linear relationship between the rate of sulphur absorption and $\log a_{\mathrm{CaO}}$ is clearly observed and the rate increases with increasing $a_{\mathrm{SiO}_{2}}$. When the activity of silica is above 0.2 , all the results are independent of the activity of silica and are represented by a line showing $a_{\mathrm{SiO}_{2}}=0.2$. Although the values of $a_{\mathrm{CaO}}$ in $\mathrm{CaO}$ $\mathrm{Al}_{2} \mathrm{O}_{3}$ slags, of which $a_{\mathrm{SiO}_{2}}$ is zero, are one order larger than those for the slags containing silica, the rates of sulphur absorption by $\mathrm{CaO}-\mathrm{Al}_{2} \mathrm{O}_{3}$ slags are in the same order as those for the slags containing silica.

On the other hand, when a graphite crucible is used as in the case of present work, it is impossible to neglect the effect of reaction between slag and graph-

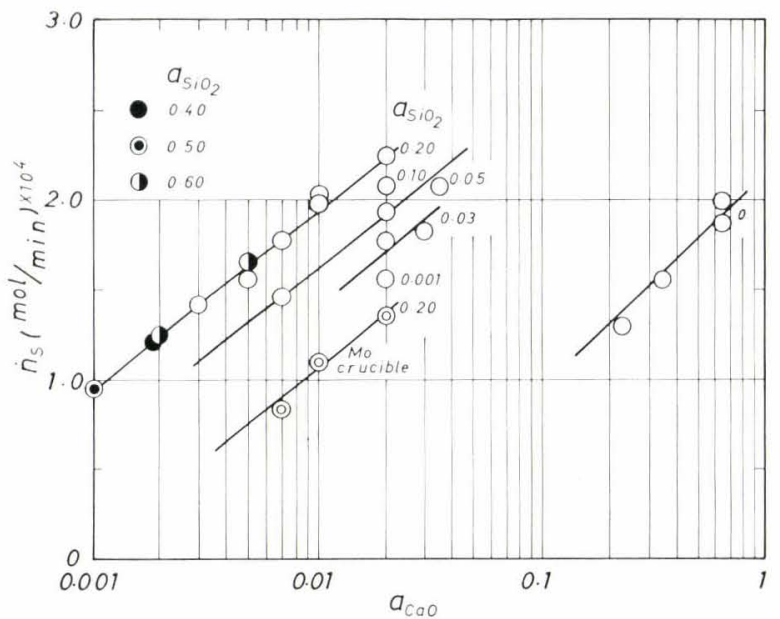

Fig. 9. Relation between $a_{\mathrm{CaO}_{2}}$ and the rate of sulphur absorption at $1550^{\circ} \mathrm{C}$

ite. Therefore, in order to determine the effect of reaction between slag and graphite, a few experiments were carried out by using a molybdenum crucible. Results obtained are shown by open circles in Fig. 8. From this figure, it can be seen that the rates of sulphur absorption are independent of the activity of silica in the slag, and are smaller than those obtained by using a graphite crucible. While, the results obtained with a molybdenum crucible under the activity of silica of 0.2 are shown by double circles in Fig. 9.

Similary, it is found that the rates of sulphur absorption by those slags with a molybdenum crucible are smaller than those obtained with a graphite crucible, and also the rates depend on the activity of lime in the slag.

These results suggest that the rate of sulphur absorption by the slag contained in a graphite crucible should depend on the reaction between the slag and graphite. As is well known, ${ }^{7}$ the rate of reduction of silica in slag by graphite is proportional to the activity of silica in slag, and it is interesting that the rate of sulphur absorption is also influenced by the reduction of silica as discussed later.

\section{Effect of Interfacial Area between Slag and Graphite}

As described above, it is probable that the effect of reaction between slag and graphite on the rate of sulphur absorption by the slag contained in a graphite crucible can not be neglected. Several experiments were therefore carried out by changing the contact area of slag and graphite by covering the inside wall of graphite crucible with a molybdenum foil. Significant oxidation or sulphurization of molybdenum during the experiment was not observed.

Although the rates of sulphur transfer to the slags such as $\mathrm{CaO}-\mathrm{SiO}_{2}(55-45)$ and $\mathrm{CaO}-\mathrm{SiO}_{2}-\mathrm{Al}_{2} \mathrm{O}_{3}$ (40-40-20) system increase linearly as the contact area between slag and graphite increases, those for $\mathrm{CaO}-\mathrm{SiO}_{2}$ (37-63) and $\mathrm{CaO}-\mathrm{Al}_{2} \mathrm{O}_{3}$ (50-50) slags were independent of the contact area as shown in Fig. 10 


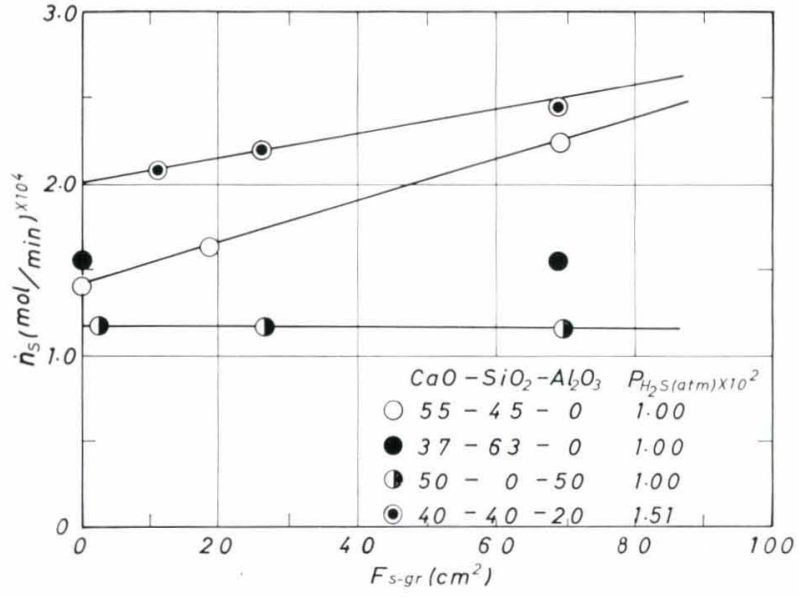

Fig. 10. Effect of interfacial area between slag and graphite on the rate of sulphur absorption into slag at $1550^{\circ} \mathrm{C}$

In the case of $\mathrm{CaO}-\mathrm{SiO}_{2}(37-63)$ slag, the deposition of $\mathrm{SiC}$ was observed on the surface of graphite, but not for the $\mathrm{CaO}-\mathrm{SiO}_{2}(55-45)$ slag. It is probable that the deposition of $\mathrm{SiC}$ on the graphite wall disturbs the reaction between slag and graphite. Accordingly, the rate of sulphur absorption by $\mathrm{CaO}$ $\mathrm{SiO}_{2}(37-63)$ slag would be independent of the contact area of slag and graphite. On the other hand, as seen from Figs. 9 and 10, the rates of sulphur absorption by $\mathrm{CaO}-\mathrm{Al}_{2} \mathrm{O}_{3}$ binary slag were independent of the reaction of slag and graphite at $1550^{\circ} \mathrm{C}$ since the reduction of silica did not occur.

\section{Effect of Temperature}

The results obtained at temperatures between $1360^{\circ}$ and $1680^{\circ} \mathrm{C}$ are shown in Fig. 11. It shows that the rate of sulphur absorption by $\mathrm{CaO}-\mathrm{SiO}_{2}$ (55-45) slag increases as the temperature increases up to $1600^{\circ} \mathrm{C}$. However, if the temperature increases above $1600^{\circ} \mathrm{C}$, the rate decreases, due probably to the deposition of $\mathrm{SiC}$ on the inside wall of graphite crucible or the increasing resistance of gas phase by the vapourization of slag component at high temperatures. For example, after the experiment at $1650^{\circ} \mathrm{C}$, it was found that the concentration of silica in $\mathrm{CaO}-\mathrm{SiO}_{2}(55-45)$ slag decreased by $5 \mathrm{wt} \%$ from the original content, and the deposition of $\mathrm{SiC}$ was observed on the inside wall of the crucible.

The rate of sulphur absorption by $\mathrm{CaO}-\mathrm{SiO}_{2}-$ $\mathrm{Al}_{2} \mathrm{O}_{3}$ (38-42-20) slag slightly increased with increasing temperature up to $1450^{\circ} \mathrm{C}$, but it became nearly constant at above $1450^{\circ} \mathrm{C}$. This may be due to the deposition of $\mathrm{SiC}$ even at the lower temperature of $1450^{\circ} \mathrm{C}$, because of the acidic slag.

On the other hand, so far as the $\mathrm{CaO}-\mathrm{Al}_{2} \mathrm{O}_{3}(55-$ 45) slag is concerned the rate of sulphur absorption decreased remarkably with increasing temperature. This would be resulted from the formation of $\mathrm{CaC}_{2}$ and also the dissolution of carbon into $\mathrm{CaO}-\mathrm{Al}_{2} \mathrm{O}_{3}$ slag from a graphite crucible. It can be seen from Fig. 12 that the dissolution of carbon remarkably proceeds as the temperature increases in the case of

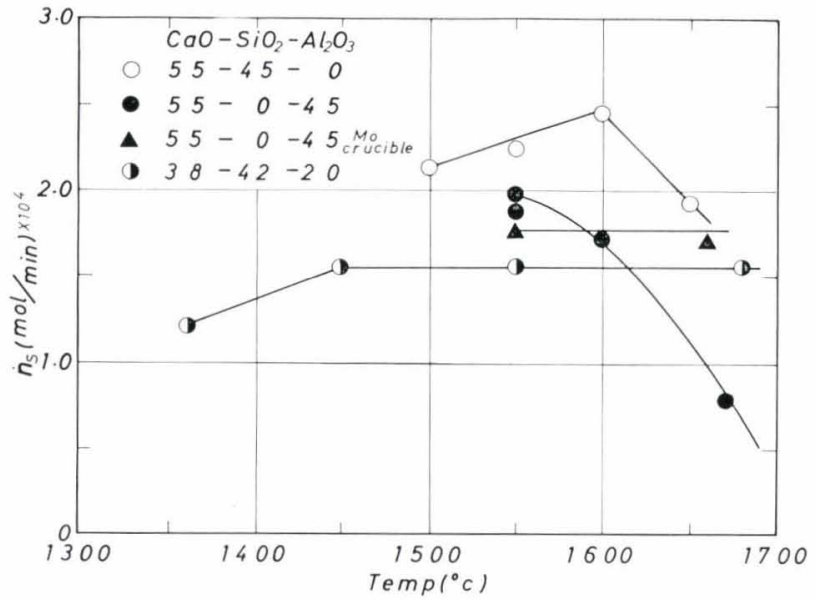

Fig. 11. Effect of temperature on the rate of sulphur absorption into slag

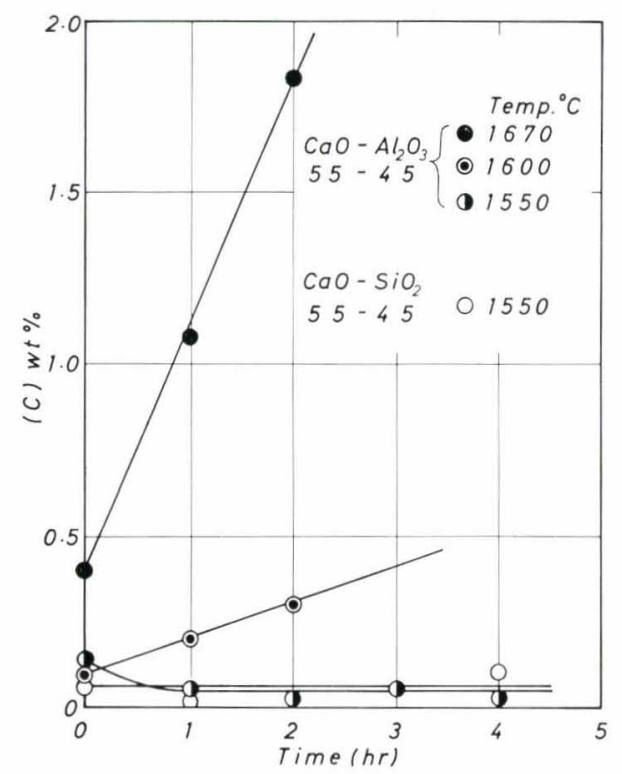

Fig. 12. Rate of carbon dissolution into binary $\mathrm{CaO}-\mathrm{SiO}_{2}$ and $\mathrm{CaO}-\mathrm{Al}_{2} \mathrm{O}_{3}$ slags

$\mathrm{CaO}-\mathrm{Al}_{2} \mathrm{O}_{3}(55-45)$ slag, but not for $\mathrm{CaO}-\mathrm{SiO}_{2}(55$ 45) slag. Similar experiments were carried out by using a molybdenum crucible and the results obtained are shown by the mark of triangle in Fig. 11, indicating that the rate of sulphur absorption does not change with increasing temperature.

\section{Discussion}

It is well known that sulphur in liquid slag exists in the form of sulphide ion or sulphate ion depending on the oxygen pressure in the gas phase. According to the literature, ${ }^{8)}$ the sulphide ion is predominantly existing when the oxygen pressure is lower than $10^{-6}$ atm but the existence of sulphate ion becomes predominant when the pressure is more than $10^{-4} \mathrm{~atm}$. These ions are coexisting when the oxygen pressure is in the range of $10^{-5}$ to $10^{-2} \mathrm{~atm}$.

Assuming that the oxygen pressure is below $10^{-6}$ atm for the present experiments, the reaction of sulphur absorption by molten slag from the gas phase can be represented by Reaction (1). 


$$
\mathrm{H}_{2} \mathrm{~S}(\mathrm{~g})+\left(\mathrm{O}^{2-}\right) \longrightarrow\left(\mathrm{S}^{2-}\right)+\mathrm{H}_{2} \mathrm{O}(\mathrm{g}) .
$$

In order to analyse the absorption kinetics, however, the following steps should be considered; (i) the transport of reaction species between bulk gas and reaction interface, (ii) chemical reaction at the interface, and (iii) transfer of sulphur from the interface to the liquid phase. The above steps are discussed below.

In the literatures, ${ }^{4,5)}$ it is generally accepted that the rate of sulphur absorption by liquid slag from gas phase is controlled by the diffusion of sulphur in the slag. The present results showed that the transfer of sulphur in the slag would be the rate controlling step, since the absorption of sulphur was clearly affected by the stirring rate when it was below $500 \mathrm{rpm}$ (see Fig. 3). In the present work, however, the most of absorption measurements were undertaken with the stirring rate of $800 \mathrm{rpm}$ in order to neglect the effect of mass transfer in the slag.

On the other hand, as seen from Fig. 5, the rate of sulphur absorption increases with increasing gas flow rate, so that the rate of sulphur absorption should be limited by the transfer of reaction species between bulk gas and reaction interface. Assuming that the transfer of $\mathrm{H}_{2} \mathrm{~S}$ in the gas phase is the rate controlling step, the rate of sulphur absorption for Reaction (1) is given by $\mathrm{Eq}$. (2).

$$
\dot{n}=\frac{D_{\mathrm{H}_{2} \mathrm{~S}}}{\delta_{G}}\left(p_{\mathrm{H}_{2} \mathrm{~S}}-p_{\mathrm{H}_{2} \mathrm{~S}}^{*} \mathrm{~s}\right.
$$

Here, $p_{\mathrm{H}_{2} \mathrm{~S}}^{*}$ at the surface of slag is regarded to be nearly zero, because the concentration of sulphur in the slag is low at the early stage of experiment, so that Eq. (2) becomes as Eq. (3).

$$
\dot{n}=\frac{D_{\mathrm{H}_{2} \mathrm{~s}}}{\delta_{G}} p_{\mathrm{H}_{2} \mathrm{~S}}
$$

As is seen from Fig. 4, the experimental results suggest that the rate of sulphur absorption should be controlled by the transfer of $\mathrm{H}_{2} \mathrm{~S}$ in the gas phase. In order to neglect the resistance for the mass transfer in the gas phase, the rate of gas flow should be increased. However, the temperature of slag surface decreases with increasing gas flow rate at above 1500 $\mathrm{cc} \cdot \mathrm{min}^{-1}$, so that the most of experiments were carried out at constant gas flow rate of $1000 \mathrm{cc} \cdot \mathrm{min}^{-1}$, to avoid the cooling effect of slag surface.

In addition, as described above, it is clear that the rate of sulphur absorption depends on the activities of lime and silica in the slag and on the material of the crucible, so the rate of sulphur absorption is controlled by the chemical reactions at the gas-slag interface and the slag-crucible interface. In the present experimental conditions, the rate of sulphur absorption should be controlled by the chemical reaction at those interfaces and by the mass transfer in the gas phase.

From the considerations mentioned above, the present work was undertaken to find the effect of slag composition on the rate of sulphur absorption under the experimental conditions described above, although

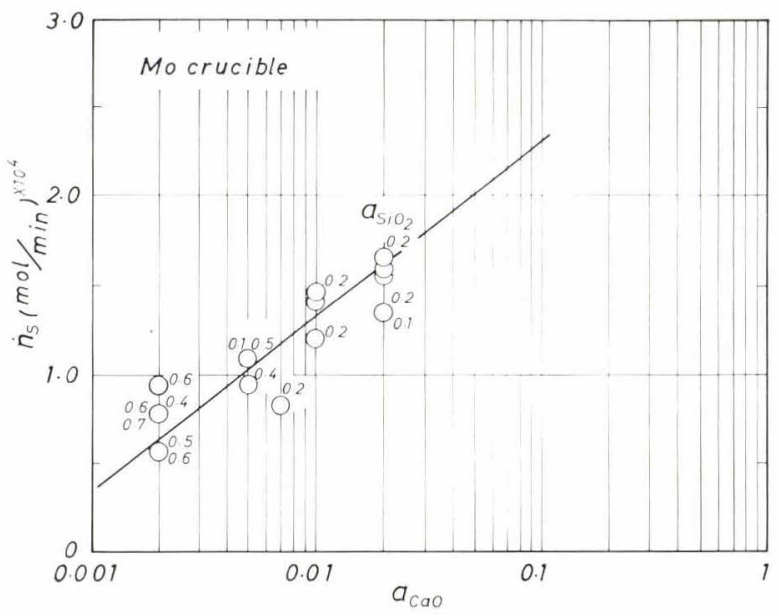

Fig. 13. Relation between $a_{\mathrm{CaO}}$ and the rate of sulphur absorption in a molybdenum crucible at $1550^{\circ} \mathrm{C}$

the overall process of sulphur absorption is mixed control.

When the chemical reaction at the gas-slag interface is given by Reaction (1), the rate equation is shown by Eq. (4).

$$
\begin{aligned}
\dot{n} & =k_{1} \cdot p_{\mathrm{H}_{2} \mathrm{~S}} \cdot a_{\mathrm{O}^{2-}}-k_{1}^{\prime} \cdot p_{\mathrm{H}_{2} \mathrm{O}} \cdot a_{\mathrm{S}^{2-}} \\
& =k_{1} \cdot p_{\mathrm{H}_{2} \mathrm{~S}}\left(a_{\mathrm{O}^{2-}}-\frac{k_{1}^{\prime}}{k_{1}} \cdot \frac{p_{\mathrm{H}_{2} \mathrm{O}}}{p_{\mathrm{H}_{2} \mathrm{~S}}} \cdot a_{\mathrm{S}^{2-}}\right) \\
& =k_{1} \cdot p_{\mathrm{H}_{2} \mathrm{~S}}\left(a_{\mathrm{O}^{2-}}-K \cdot \frac{p_{\mathrm{H}_{2} \mathrm{O}}}{p_{\mathrm{H}_{2} \mathrm{~S}}} \cdot a_{\mathrm{S}^{2-}}\right) .
\end{aligned}
$$

If Reaction (1) proceeds at steady state, it can be considered that $p_{\mathrm{H}_{2} \mathrm{O}} / p_{\mathrm{H}_{2} \mathrm{~S}}$ is constant. Also $a_{\mathrm{S}^{2-}}$ is practically zero at the first stage of experiment, because of low concentration of sulphur. Then Eq. (4) can be rewritten as Eq. (5).

$$
\dot{n}=k_{1} \cdot p_{\mathrm{H}_{2} \mathrm{~S}} \cdot a_{\mathrm{O}^{2-}} .
$$

The results obtained by using a molybdenum crucible, in which reaction between the melt and crucible material does not occur, are shown in Fig. 13. It can be seen that the rate of sulphur absorption depends on the activity of lime in the slag. Then, the experimental rate equation becomes

$$
\dot{n}_{s}^{\circ}=k_{1}^{*} \cdot p_{\mathrm{H}_{2} \mathrm{~s}} \cdot a_{\mathrm{CaO}}
$$

This equation is regarded as a rate equation of the absorption of sulphur by slag.

Comparing Eq. (5) with Eq. (5'), it is clear that, when $a_{\mathrm{CaO}}$ is constant, the rate of sulphur absorption is proportional to $p_{\mathrm{H}_{2} \mathrm{~S}}$ and if $p_{\mathrm{H}_{2} \mathrm{~S}}$ is constant, the rate becomes to be proportional to $a_{\mathrm{caO}}$.

However, the following points should be taken into account for the analysis of the results obtained by the use of a graphite crucible:

(1) Although the activity of lime in $\mathrm{CaO}-\mathrm{Al}_{2} \mathrm{O}_{3}$ slag is larger than that in $\mathrm{CaO}-\mathrm{SiO}_{2}$ slag, the rate of sulphur absorption by $\mathrm{CaO}-\mathrm{Al}_{2} \mathrm{O}_{3}$ slag is smaller than that by $\mathrm{CaO}-\mathrm{SiO}_{2}$ slag.

(2) In the case that the activity of lime is the same, the rate is proportional to the activity of silica, 
when the activity of silica is below 0.2 .

(3) The rate obtained by using a graphite crucible is larger than that determined with a molybdenum crucible.

(4) The rate depends on the contact area of slag and graphite.

In order to explain these results, some reactions between slag and graphite should be considered. The reactions accompanied are the reduction of silica, the deposition of carbide and the dissolution of carbon in slag. The effects of these reactions on the rate of sulphur absorption by slag are considered as follows.

The rate equation of Reaction (1) is given by Eq. (5), and if $p_{\mathrm{H}_{2} \mathrm{~S}}$ is constant, the behaviour of $a_{\mathrm{O}^{2-}}$ in slag plays an important role on the absorption reaction of sulphur. Therefore, the effects of the interfacial reactions between slag and graphite on the rate of sulphur absorption could be clarified, if the behaviour of $\mathrm{O}^{2-}$ ion in slag is taken into account.

The reduction of silica by graphite is shown as follows;

$$
\begin{aligned}
\left(\mathrm{SiO}_{4}^{4-}\right)+\mathrm{C}_{\mathrm{gr}} & \longrightarrow \mathrm{SiO}(\mathrm{g})+2\left(\mathrm{O}^{2-}\right)+\mathrm{CO}(\mathrm{g}) \\
\left(\mathrm{SiO}_{4}^{4-}\right)+3 \mathrm{C}_{\mathrm{gr}} & \longrightarrow \mathrm{SiC}(\mathrm{s})+2\left(\mathrm{O}^{2-}\right)+2 \mathrm{CO}(\mathrm{g})
\end{aligned}
$$

In either case, the reduction of silica produces $\mathrm{O}^{2-}$ ion and the content of silica in slag is apt to decrease. Consequently the activity of lime increases, and the reaction of sulphur absorption in those slags is promoted by the reduction of silica .

According to the kinetic study on the reduction of silica in liquid slag by carbon, it is accepted that the reduction rate increases with increasing contact area of slag and graphite. In the present work, the rate of the reduction of silica is given by $\mathrm{Eq}$. (8).

$$
\dot{n}_{\mathrm{SiO}_{2}}=k_{2} \cdot a_{\mathrm{SiO}_{2}}
$$

From Eqs. (5') and (8), the rate of sulphur absorption accompanying the reduction of silica is given by Eq. (9).

$$
\begin{aligned}
\dot{n}_{s} & =\dot{n}_{s}^{\circ}+\dot{n}_{r} \\
& =k_{1}^{*} \cdot p_{\mathrm{H}_{2} \mathrm{~S}}\left(a_{\mathrm{CaO}}+\beta \cdot a_{\mathrm{SiO}_{2}}\right)
\end{aligned}
$$

where $\beta$ is equal to $k_{2} / k_{1}^{*}$. Then Eq. (9) becomes

$$
\frac{\dot{n}_{8}}{a_{\mathrm{SiO}_{2}}}=k_{3} \cdot \frac{a_{\mathrm{CaO}}}{a_{\mathrm{SiO}_{2}}}+k_{4}
$$

where, $k_{3}: k_{1}^{*} \cdot p_{\mathrm{H}_{2} \mathrm{~S}}$

$$
k_{4}: \quad k_{1}^{*} \cdot p_{\mathrm{H}_{2} \mathrm{~S}} \mathrm{~s} \cdot \beta \text {. }
$$

Applying the experimental results to Eq. (9'), a linear relationship was obtained as shown in Fig. 14 and its gradient gives $k_{3}=7.96 \times 10^{-3}\left(\mathrm{~mol} \cdot \mathrm{min}^{-1}\right)$ and the intersection on the vertical axis gives $k_{4}=$ $5.4 \times 10^{-4}\left(\mathrm{~mol} \cdot \mathrm{min}^{-1}\right)$.

Here, the effect of the deposition of such carbides as $\mathrm{SiC}$ and $\mathrm{CaC}_{2}$ on the rate of sulphur absorption is taken into account. When $\mathrm{CaO}-\mathrm{SiO}_{2}(55-45)$ and $\mathrm{CaO}-\mathrm{SiO}_{2}$ (37-63) slags were melted in a graphite crucible at $1650^{\circ} \mathrm{C}$ and $1550^{\circ} \mathrm{C}$ respectively, $\mathrm{SiC}$ was observed at the slag-graphite interface. It was confirmed the existence of carbides by X-ray analysis, but $\mathrm{CaC}_{2}$ was not found.

The reactions of carbon dissolution into liquid slag are given as follows: $:^{9,10)}$

$$
\begin{aligned}
& 2 \mathrm{C}_{\mathrm{gr}}+\left(\mathrm{O}^{2-}\right) \longrightarrow\left(\mathrm{C}^{2-}\right)+\mathrm{CO}(\mathrm{g}) \\
& 3 \mathrm{C}_{\mathrm{gr}}+\left(\mathrm{O}^{2-}\right) \longrightarrow\left(\mathrm{C}_{2}^{2-}\right)+\mathrm{CO}(\mathrm{g})
\end{aligned}
$$

As it is clear from the above reactions, the carbon dissolution should consume the oxygen ion in slag. Consequently, $a_{\mathrm{O}^{2-}}$ in Eq. (5) decreases and the rate of sulphur absorption also decreases when the absorption of sulphur by slag proceeds with the carbon dissolution.

When the rate of carbon dissolution is given by $\dot{n}_{c}$ and is substituted into Eq. (9), the rate equation of sulphur absorption is given by Eq. (12).

$$
\dot{n}_{s}=\dot{n}_{s}^{\circ}+\dot{n}_{r}-\gamma \cdot \dot{n}_{c}
$$

If the reduction of silica does not occur during the sulphur absorption, for example, the case of $\mathrm{CaO}$ $\mathrm{Al}_{2} \mathrm{O}_{3}$ (55-45) slag, the relationship of Eq. (12) is clearly observed as shown in Fig. 15. This figure also indicates that the relationship between the rate of sulphur absorption and the rate of carbon dissolution

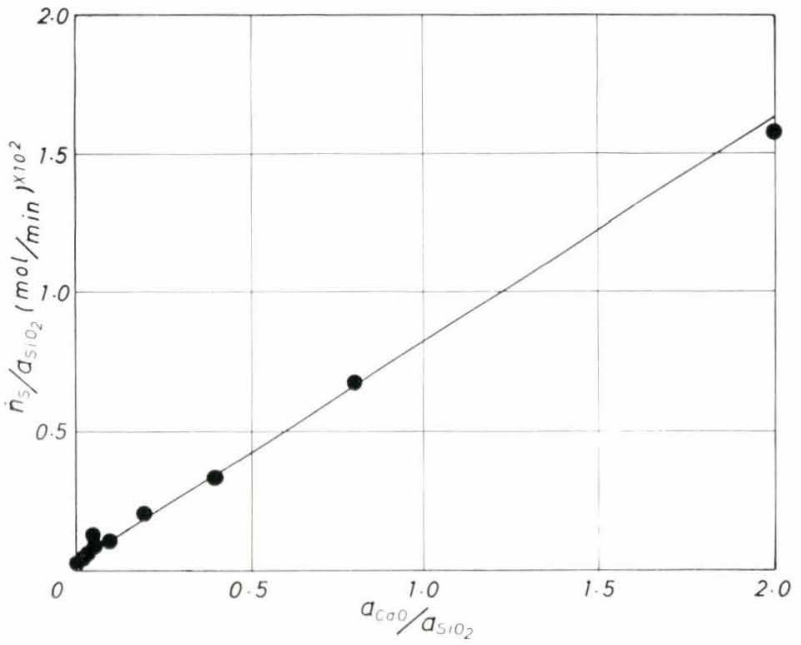

Fig. 14. Relation between $a_{\mathrm{CaO}} / a_{\mathrm{SiO}_{2}}$ and $\dot{n}_{s} / a_{\mathrm{SiO}_{2}}$ at $1550^{\circ} \mathrm{C}$

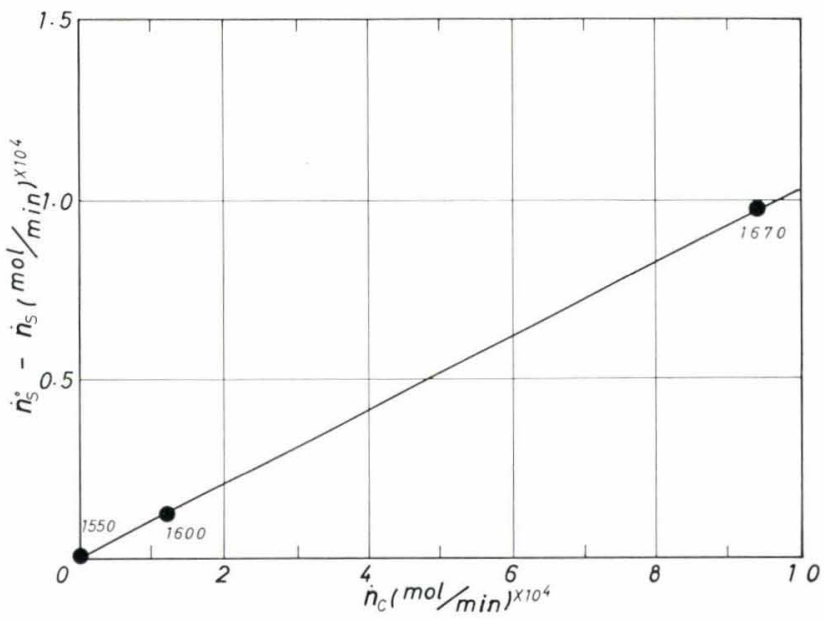

Fig. 15. Relation between $\dot{n}_{c}$ and $\dot{n}_{s}^{\circ}-\dot{n}_{s}$ for $\mathrm{CaO}-\mathrm{Al}_{2} \mathrm{O}_{3}$ (55-45) slag 
is independent of temperature.

Consequently, it is concluded that the rate of sulphur absorption increases with the progress of the silica reduction, but decreases as the carbon dissolution proceeds in a graphite crucible.

\section{Comparison with the Absorption of Nitrogen in Slag}

It is well known that nitrogen is absorbed in liquid slag under a reducing atmosphere. Recently, some experimental works on the nitrogen absorption in liquid slags have been reported. ${ }^{11-15)}$ Those results show that nitrogen dissolves into liquid slag in the form of $\mathrm{N}^{3-}, \mathrm{CN}_{2}^{2-}$ or $\mathrm{CN}^{-}$ion under a reducing atmosphere.

It is also stated that the reaction of nitrogen dissolution can be expressed as follows ;11,12)

$$
\begin{gathered}
3 \mathrm{C}_{\mathrm{gr}}+3\left(\mathrm{O}^{2-}\right)+\mathrm{N}_{2} \rightleftarrows 2\left(\mathrm{~N}^{3-}\right)+3 \mathrm{CO} \\
2 \mathrm{C}_{\mathrm{gr}}+\left(\mathrm{O}^{2-}\right)+\mathrm{N}_{2} \rightleftarrows\left(\mathrm{CN}_{2}^{2-}\right)+\mathrm{CO} \\
3 \mathrm{C}_{\mathrm{gr}}+\left(\mathrm{O}^{2-}\right)+\mathrm{N}_{2} \rightleftarrows 2\left(\mathrm{CN}^{-}\right)+\mathrm{CO}
\end{gathered}
$$

Previously, T. Choh et al. ${ }^{14)}$ studied the contribution of the reaction at the slag-graphite interface to the rate of nitrogen absorption by considering such elementary reactions as Eqs. (14) to (16).

$$
\begin{aligned}
& 3 \mathrm{C}_{\mathrm{gr}}+\left(\mathrm{O}^{2-}\right) \rightleftarrows \mathrm{C}_{2}^{2-}+\mathrm{CO} \\
& \mathrm{C}_{2}^{2-} \rightleftarrows 2 \mathrm{C}_{(\mathrm{pr})}+2 e \\
& \mathrm{C}_{(\mathrm{pr})}+\left(\mathrm{O}^{2-}\right) \rightleftarrows \mathrm{CO}+2 e \ldots
\end{aligned}
$$

They showed that those reactions represented by Eq. (17) were also valid besides Eq. (13) to explain the mechanism of nitrogen absorption at the slag-gas interface.

$$
\begin{aligned}
\left(\mathrm{C}_{2}^{2-}\right)+\mathrm{N}_{2} & \rightleftarrows\left(\mathrm{CN}_{2}^{2-}\right)+\mathrm{C}_{(\mathrm{pr})} \\
3\left(\mathrm{C}_{2}^{2-}\right)+\mathrm{N}_{2} & \rightleftarrows 2\left(\mathrm{~N}^{3-}\right)+6 \mathrm{C}_{(\mathrm{pr})} \\
\left(\mathrm{C}_{2}^{2-}\right)+\mathrm{N}_{2} & \rightleftarrows 2\left(\mathrm{CN}^{-}\right)
\end{aligned}
$$

From those expressions it is reasonable to consider that the reductive reaction of $\mathrm{O}^{2-}$ ion in the slag under a reducing atmosphere is required for nitrogen absorption. On the contrary, it is not necessary for sulphur absorption as in the case of the present work. However, so far as the rate of absorption is concerned, the rate of sulphur absorption as well as that of nitrogen absorption increases with an increase in the number of $\mathrm{O}^{2-}$ or the concentration of $\mathrm{CaO} .{ }^{12-14}$ ) $\mathrm{On}$ the other hand, it was observed that the rates of nitrogen absorption by the ternary liquid $\mathrm{CaO}-\mathrm{Al}_{2} \mathrm{O}_{3}-$ $\mathrm{SiO}$, slag decreases with increasing silica content in the slag. This is not the case of sulphur absorption.

Consequently, the transfer of nitrogen is controlled mainly by the reduction of $\mathrm{O}^{2-}$ ion, but the effect of silica reduction is small. Furthermore, the rate of nitrogen absorption increases when the simultaneous dissolution of carbon into slag occurs; ${ }^{14,16)}$ however, the rate of sulphur absorption rather decreases.

\section{Conclusion}

From the standpoint of the reaction taking place in the blast furnace, the transfer of sulphur into molten slag from $\mathrm{Ar}-\mathrm{H}_{2} \mathrm{~S}$ gas mixture under a reducing atmosphere was studied and the following results were obtained.

The amount of sulphur absorbed from the gas phase lineary increases with the elapse of time, depending on the partial pressure of hydrogen sulphide and the gas flow rate. The absorption rate is increased by the sulphur transfer in the liquid slag phase and appears to be constant when the stirring rate is above $500 \mathrm{rpm}$.

Generally, the rate of sulphur absorption is influenced by the slag composition. In the binary slag system, such as $\mathrm{CaO}-\mathrm{SiO}_{2}$ or $\mathrm{CaO}-\mathrm{Al}_{2} \mathrm{O}_{3}$, the absorption rate increases with increasing $\mathrm{CaO}$ content. It is also found that the rate of sulphur absorption by $\mathrm{CaO}-\mathrm{SiO}_{2}$ slag is larger than that by $\mathrm{CaO}-\mathrm{Al}_{2} \mathrm{O}_{3}$ slag. With regard to $\mathrm{CaO}-\mathrm{SiO}_{2}-\mathrm{Al}_{2} \mathrm{O}_{3}$ ternary slag, the absorption rate depends on the activity of lime and also the activity of silica, and the overall transfer rate is given by the product of $p_{\mathrm{H}_{2} \mathrm{~S}}$ and the activity of $\mathrm{O}^{2-}$ ion.

The rate of sulphur absorption increases with increasing slag-graphite interfacial area; however, it decreases, if the slag is accompanied with the dissolution of carbon as in the case of $\mathrm{CaO}-\mathrm{Al}_{2} \mathrm{O}_{3}$ slag.

An increase in temperature does not always accelerate the absorption rate, but retards the rate because of the dissolution of carbon into slag and the vapourization of slag components.

\section{Nomenclature}

$a_{i}:$ activity of species $i$

$C_{\mathrm{pr}}$ : precipitating carbon

$D_{j}$ : diffusion coefficient of species $j\left(\mathrm{~cm}^{2} / \mathrm{sec}\right)$

$k$ : reaction rate constant $(\mathrm{mol} / \mathrm{min})$

$K$ : equilibrium constant

$\dot{n}_{s}$ : rate of sulphur absorption $(\mathrm{mol} / \mathrm{min})$

$\dot{n}_{s}^{\circ}$ : rate of sulphur absorption without accompanying reaction $(\mathrm{mol} / \mathrm{min})$

$\dot{n}_{\mathrm{SiO}_{2}}:$ rate of silica reduction $(\mathrm{mol} / \mathrm{min})$

$\dot{n}_{r}$ : rate of silica reduction $(\mathrm{mol} / \mathrm{min})$

$\dot{n}_{e}$ : rate of carbon dissolution $(\mathrm{mol} / \mathrm{min})$

$p_{\mathrm{H}_{2} \mathrm{~S}}$ : partial pressure of $\mathrm{H}_{2} \mathrm{~S}$ in gas bulk (atm)

$p_{\mathrm{H}_{2} \mathrm{~S}}^{*}$ : partial pressure of $\mathrm{H}_{2} \mathrm{~S}$ at interface (atm)

$p_{\mathrm{H}_{2} \mathrm{O}}$ : partial pressure of $\mathrm{H}_{2} \mathrm{O}$ in gas bulk (atm)

$\beta, \gamma$ : proportional constant

$\delta_{\mathrm{G}}$ : thickness of gaseous boundary layer $(\mathrm{cm})$

\section{Acknowledgements}

The authors wish to acknowledge the grant from the Ministry of Education which supported this research work.

\section{REFERENCES}

1) Y. Shimomura, K. Nishikawa, S. Arino, T. Katayama, Y. Hida and T. Isoyama: Tetsu-to-Hagané, 62 (1976), 547.

2) F. D. Richardson and J. B. Fincham: Proc. Roy. Soc., 223 (1954), 40 .

3) F. D. Richardson and J. B. Fincham: JISI, 178 (1958), 4.

4) E. T. Turkdogan and M. L. Pearce: Trans. Met. Soc. AIME, 227 (1963), 940. 
5) A. S. Alwan and P. M. Bills: JISI, 202 (1964), 367.

6) R. H. Rein and J. Chipman: Trans. Met. Soc. AIME, 233 (1965), 415.

7) M. Ashizuka, M. Tokuda and M. Ohtani: Tetsu-to-Hagané, 54 (1968), 1437.

8) E. T. Turkdogan and L. S. Darken: Trans. Met. Soc. AIME, 221 (1961), 464.

9) J.H. Swisher: Trans. Met. Soc. AIME, 242 (1968), 2033.

10) H. G. Schubert and K. Schwerdfeger: Arch. Eisenhüttenw., 45 (1974), $437 \& 499$.

11) S. K. Cucmarev, O. A. Esin and V. M. Kamysov: Izv.
VUZov Cher. Met., (1965) No. 25.

12) A. Majdic, W. J. Ammerling and H. Schenk: Arch. Eisenhüttenw., 41 (1970), 11.

13) T. Simoo, H. Kimura and M. Kawai: J. Japan Inst. Metals, 36 (1972), 723 \& 728.

14) T. Choh, Y. Hanaki, T. Kato and M. Inouye: Trans. ISIJ., 13 (1973), 218.

15) K. Schwerdfeger and H. G. Schubert: Arch. Eisenhüttenw,, 45 (1974), 649.

16) T. Shimoo, H. Kimura and M. Kawai: J. Japan Inst. Metals, 38 (1974), 1115. 